\title{
School Social Workers as Response to Intervention Change Champions
}

\author{
Deneca Winfrey Avant \\ Brenda Coble Lindsey
}

\begin{abstract}
School social workers (SSWs) are known for serving students with social, emotional, and academic needs. Implementing Response to Intervention (RTI)/MultiTiered System of Supports (MTSS) is one avenue in which SSWs play an integral role by guiding the development and implementation of student interventions. RTI/MTSS requires substantive and multifaceted system changes that involve more than simply adopting new approaches. This paradigm shift brings change which may not be desired or easily accepted by school systems. However, developing collaborative relationships and using effective leadership strategies throughout the RTI/MTSS transformation can be a pathway to success. A survey of 192 SSWs in Illinois revealed the challenges that SSWs experienced as the process of implementing RTI/MTSS transformed them into change leaders. This revelation was viewed as an opportunity to closely align social and emotional practices with students' academic achievement.
\end{abstract}

Keywords: Change agents, leaders, Multi-Tiered System of Supports, Response to Intervention, school social workers

Life in schools is about changes, challenges, and the ability to preserve order. As change agents, school social workers (SSWs) are largely responsible for nurturing young minds both socially and academically (Alfred, Slovak, \& Broussard, 2010). Students' social habits, lifestyles, school performance, and psychological and emotional needs have changed substantially from the past (Bridgeland, Bruce, \& Hariharan, 2013). Because the current generation of students is being faced with more social media influences, mental health concerns, bullying, and issues at home, there has been an increase in identified learning and behavioral problems (Zosky, Avant, \& Thompson, 2014). As a result of these changes and mandated federal policies, schools have been pushed to incorporate new evidence-based interventions to properly serve student needs (Sabatino, Kelly, Moriarity, \& Lean, 2013). Response to Intervention (RTI)/Multi-Tiered System of Supports (MTSS) is one example of adhering to this new obligation. RTI/MTSS is leading the nation in altering our approach to resolving barriers and supporting student success (Clark \& Tilly, 2010; Sugai \& Horner, 2010).

RTI/MTSS is a multi-level system-wide approach that focuses on students at risk for poor learning outcomes by monitoring progress and providing evidence-based interventions (Batsche et al., 2006). The purpose of RTI/MTSS is to identify learning and behavioral problems and then integrate assessments and interventions that provide students with the best school opportunities. Problem-solving teams are key factors in effective RTI/MTSS implementation (Nellis, 2012). Best practice is to have team members represent a wide variety of disciplines including teachers, principals, SSWs, and other school specialists (Burns, Wiley, \& Viglietta, 2008).

Deneca Winfrey Avant, Ph.D., is an Assistant Professor in the School of Social Work at Illinois State University in Normal, IL. Brenda Coble Lindsey, Ed.D., is a Clinical Associate Professor in the School of Social Work at the University of Illinois at Urbana-Champaign, IL.

Copyright @ 2015 Advances in Social Work Vol. 16 No.2 (2015), 276-291, DOI: 10.18060/16428 
SSWs play a unique role in expediting RTI/MTSS and intervening in the educational process at multiple levels (Clark, Alvarez, Marckmann, \& Timm, 2010; Kelly et al., 2010). As active participants on school leadership teams, SSWs may solely design or be integral contributors to RTI/MTSS processes. RTI/MTSS implementation has pushed the expansion of social work services from traditional roles of providing individual and group counseling, school and community consultations, and crisis interventions to becoming change champions (Clark \& Alvarez, 2010). A change champion is someone who plays a pivotal role in advancing adoption of new ideas in organizations (Rogers, 2003). They have considerable influence over others and hold key linking positions within their organizations. Because SSWs have excellent leadership skills in facilitation and coordination of change efforts, they are well-positioned to guide RTI/MTSS implementation.

Although RTI/MTSS is strongly encouraged by the federal government and mandated in numerous states, many teachers and staff are reluctant to embrace the approach as educational change (Greenfield, Rinaldi, Proctor, \& Cardarelli, 2010; Landon, 2010). Change is often difficult to implement because of barriers that people place between themselves and change efforts (Fullan, 2007). School personnel have traditions and become comfortable with the way issues are handled (Winfrey, 2011). Stability is seen as desirable; therefore, being content and maintaining status quo may be preferred over change. Some individuals may resist adopting RTI/MTSS because they do not understand the rationale for change. Effective change is the result of increasing the capacity of individuals and organizations to know when and how to pursue and implement change. Moreover, the psychological process of accepting and learning new ways of operating is typically a slow process. Regardless of whether the decision to adopt RTI/MTSS is enthusiastically or reluctantly perceived, it may involve loss, anxiety, and struggle for those involved in its implementation. Such emotional reactions are a natural response to change.

SSWs are uniquely qualified to play key roles in the RTI/MTSS change process because they have a holistic understanding of how schools work. This attention to detail includes developing collaborative relationships with teachers and using effective strategies to engage them throughout the transformation (Harris, Franklin, \& Lagana-Riordan, 2010). By using a systems perspective, understanding the whole child, and managing school-wide behavior interventions, SSWs are able to facilitate RTI/MTSS implementation. SSWs can take the lead by identifying and ameliorating challenges experienced during major changes required at schools (Clark \& Tilly, 2010; Peckover, Vasquez, Van Housen, Saunders, \& Allen, 2013).

\section{Literature Review}

RTI/MTSS refers to school-wide application of academic and behavioral interventions that promote assistance to children having difficulty learning (Batsche et al., 2006; Ridgeway, Price, Simpson, \& Rose, 2012). Sugai and Horner (2002) suggested that schools interested in implementing RTI/MTSS are best served by adopting a systems perspective and developing a common set of desired academic and behavioral expectations for students. Schools accomplish this through administrative support coupled with team-based problem-solving approaches, research-validated practices, and data-based decision-making processes. These strategies ensure a congruent school-wide approach to prevent academic 
failure and encourage students to display socially appropriate behaviors while reducing the likelihood that challenging behaviors will occur (Lindsey, 2008).

RTI/MTSS uses a three tier model to apply this integrated approach (Batsche et al., 2006; Brown-Chidsey \& Steege, 2005; Sugai \& Horner, 2002) (see Figure 1). Tier one interventions are universal to all students and aim to prevent academic and behavioral problems. Examples of tier one interventions include research-based, social-emotional learning curricula taught in general education classrooms. These interventions provide students with methods to display expected behaviors, proactively pre-correct students, and acknowledge them for exhibiting expected behaviors. The RTI/MTSS model anticipates that $80-90 \%$ of students will respond to tier one interventions (Lindsey, 2008).

Tier two interventions are short-term and individualized, such as Check \& Connect, which targets students at risk of displaying problems including reading below grade level or poor social skills (Alvarez \& Anderson-Ketchmark, 2010; Eber, Lindsey \& White, 2010). These interventions are designed to bring about rapid improvement and be quickly accessed, highly efficient, and flexible (Hawken \& Horner, 2003; McIntosh, Campbell, Carter, \& Dickey, 2009). RTI/MTSS estimates that $10-15 \%$ of students will need tier two interventions to be successful in school (Center for Mental Health in Schools at UCLA, 2011). Tier two interventions include specially designed small group counseling provided by SSWs, school psychologists, school counselors, and other behavioral specialists (Crone, Hawken, \& Horner, 2010; Lindsey, 2008).

Tier three interventions are provided to students with highly intensive academic and behavioral needs. These interventions are developed based on unique student needs and are likely to be long-term (Eber et al., 2010; Malloy, Sundar, Hagner, Pierias \& Viet, 2010; Scott \& Eber, 2003). Interventions include Rehabilitation, Empowerment, Natural Supports, Education, and Work (RENEW, Malloy et al., 2010). RENEW is an application of the wraparound planning process based on student strengths and needs across home, school, and community contexts. The RTI/MTSS framework anticipates that $1-5 \%$ of students will require tier three interventions. All three tiers work together to provide a continuum of school-wide instructional and behavioral supports that most likely come under the lead of SSWs. This three-tiered intervention for effective school environments is demonstrated by Sugai, Horner, and Gresham (2002) as shown in Figure 1. 
Figure 1. Designing School-Wide Support Systems for Student Success

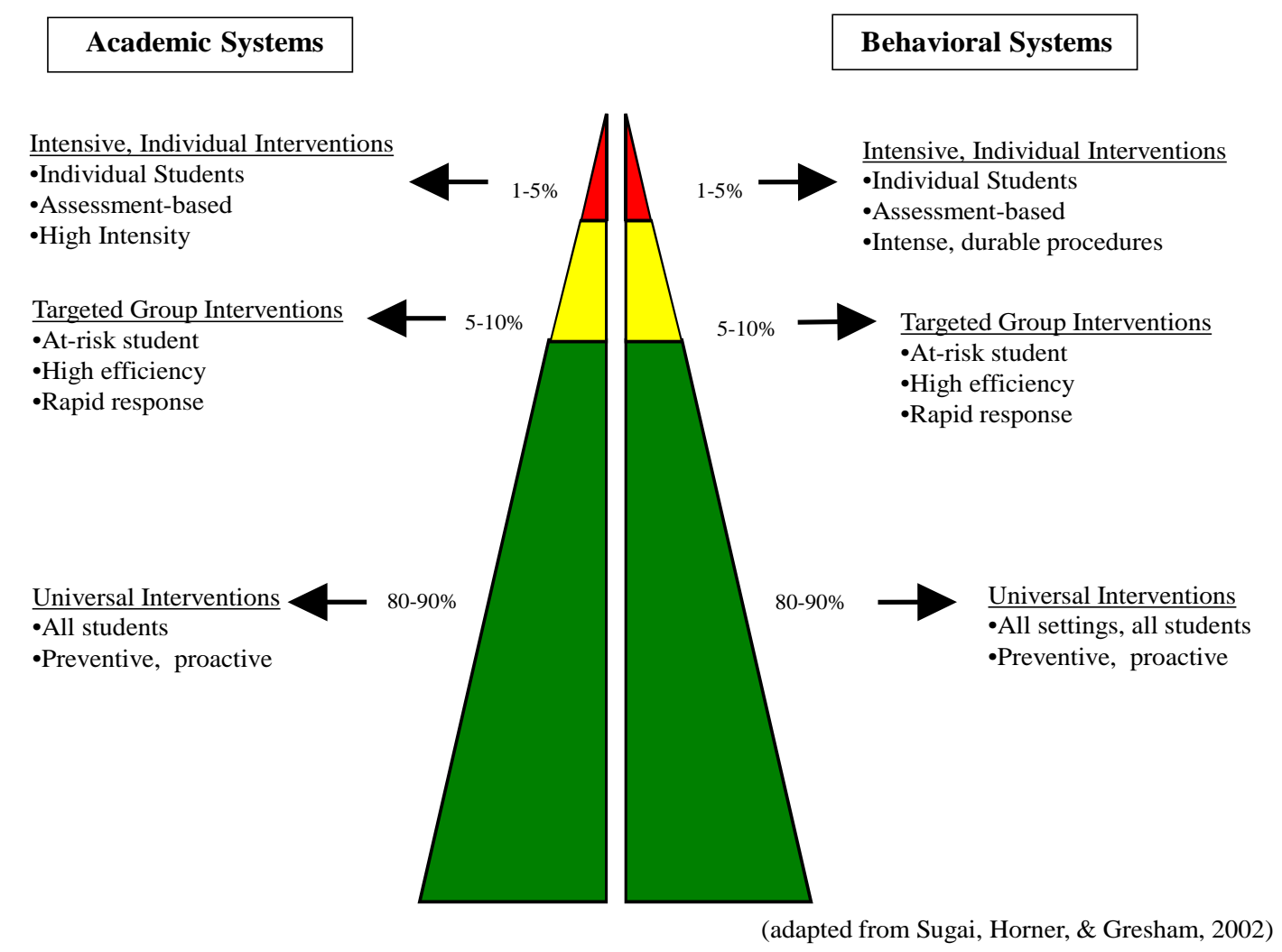

A critical ingredient for accurate and sustained RTI/MTSS implementation is to provide coaching to teachers and staff in becoming proficient in the application of all three tiers (University of South Florida, 2011). Coaches are responsible for supporting schools and RTI/MTSS implementation teams. They do this by creating positive and productive team environments, facilitating consensus for decisions, guiding meaningful problemsolving processes, and providing access to training and resources. Schools are more likely to successfully implement RTI/MTSS when they adopt organized and systematic coaching models (University of South Florida, 2011).

\section{School Social Work Leadership}

The RTI/MTSS framework is dramatically changing expectations for related-service providers (Clark \& Alvarez, 2010; Frey, Lingo, \& Nelson, 2008), especially the profession of SSWs. Historically, SSWs have had a great deal of flexibility in the strategies, interventions, and methods they use to remove learning barriers (Kelly et al., 2010). RTI/MTSS brings consistency to school-wide curriculum, programs, and practices; it also affords SSWs key leadership opportunities to demonstrate specialized skills working with students experiencing behavioral challenges (Lawson, 2010). In practice, this means SSWs incorporate evidence-based approaches that are identified and evaluated based on data and are focused on the whole child (Lawson, 2010; Raines, 2004, 2008). 
RTI/MTSS requires concurrent changes in school organizational structures and learning environments that need to be achieved without discord. Such changes need to be viewed from within a person-in-environment framework (Lawson, 2010). SSWs are uniquely prepared for this challenge because of their knowledge and skills in problem assessment and interventions, their understanding of the relationship between academics and behaviors, and their familiarity with the person-in-environment framework that is an intrinsic part of RTI/MTSS. Moreover, as change leaders, SSWs are familiar with factors that influence successful implementation of new school programs and approaches. For these reasons, SSWs may be in the best position to champion student achievement and promote school reform.

\section{Diffusion of Innovations}

Diffusion of innovations is the process by which new initiatives are adopted by organizations, customers, or clients (Rogers, 2003). It can be applied to decisions made by individual consumers about whether to buy the latest technology or to decisions made by school districts on adopting RTI/MTSS (Lindsey, 2008). Diffusion of innovations encompasses a number of factors including: the innovation itself, how information is relayed to others, the point in time that the innovation emerges, and the characteristics of potential users (Rogers, 2003). In reality, the true quality of the innovation is not as important as the user's perception of its worth (Lindsey, 2008).

Once a school district decides to introduce RTI/MTSS, implementation does not typically follow a linear path (Landon, 2010). Because the organizational change process requires a number of individuals to work together, it is highly complex (Rogers, 2003). Implementation of innovations within schools requires both the innovation and the organization to change in order to facilitate goodness-of-fit.

A “change champion” plays a critical role in bringing about successful implementation (Rogers, 2003). Such a person must have an established interpersonal network that provides ongoing opportunities for collaboration and consultation with key staff. They should be politically astute and understand informal patterns of relationships and alliances between members of the organization. Champions must also possess excellent communication and negotiation skills that enable them to work effectively with a wide range of interests and people. Many times an innovation must be reworked to better fit the needs of a particular organization. A champion can facilitate this process by employing his or her people skills to organize a coalition of individuals that will ensure the implementation process goes smoothly. SSWs exhibit these characteristics and thus are a logical choice to assume the pivotal role of RTI/MTSS leader or change champion.

As an innovation, RTI/MTSS requires organizational structures in schools to change in order to accommodate the approach. Frequently, the degree of change required is underestimated. Substantive change does not occur overnight. It is a delicate process that involves time and careful navigation. Change means transition which requires people to adjust their thoughts, attitudes, and behavior, (Winfrey, 2011). The change process for major school restructuring consists of initiation followed by implementation to continuation and evaluation of outcomes (Fullan, 2007). For RTI/MTSS to become embedded within the school culture, staff must acquire a deeper understanding of the type 
of changes that are truly required. Kotter (1996) indicates, "new approaches usually sink into a culture only after it's very clear that they work and are superior to old methods" (p. 157). Only after school staff are convinced that RTI/MTSS is superior to previous policies and practices will it become ingrained. Innovations cannot exist without trust, confidence, consistency, and integrity (Evans, 2000). These values, characterized by personal ethics, vision, and belief in others, are fundamental components of both leadership and the social work profession (Evans, 2000). SSWs are often skillful in generating trust, which is critical to be effective change leaders. By understanding the issues, concerns, barriers, and challenges associated with widespread organizational transformation, SSWs can facilitate the systemic changes required for RTI/MTSS. Teachers tend to resist changing for a future they cannot clearly see (Lunenburg \& Ornstein, 2007). According to Knight (2009), teachers usually need to experience success and believe that change is powerful with easily implemented programs or practices. Because of the massive changes required to implement RTI/MTSS, SSWs are well-equipped to shepherd the change process and generate buy-in from teachers and staff.

As RTI/MTSS is now mandated within the State of Illinois, schools are transitioning to evidence-based assessments and interventions for students with learning and behavioral problems. Due to the major systemic changes that are necessary for the success of RTI/MTSS, all staff roles and responsibilities may be altered, especially those of SSWs. This transformation has forced SSWs into leadership roles. Because SSWs play a unique role in expediting RTI/MTSS, their perspective is critical in understanding the challenges and accomplishments of RTI/MTSS. While many studies discuss staff roles and RTI/MTSS implementation (Avant, 2014; Kelly et al., 2010), there appears to be a significant gap in the literature regarding how SSWs' roles and responsibilities are influenced. This research study examined how SSWs perceive the advantages, disadvantages, and challenges of implementing RTI/MTSS.

\section{Methods}

This study used survey research with a 32-item questionnaire composed of open and forced-choice responses. Sample items include: (a) Describe the potential gains and disadvantages of implementing RTI, (b) How has RTI limited and/or increased your SSWs' roles?, (c) Did you receive formal training on implementing RTI?, and (d) What form of RTI supports are provided by your school? Question construction was based on a review of RTI/MTSS and school social work practice literature, as well as an Illinois Association of School Social Workers (IASSW) University Relations Committee discussion. This committee, which served as an advisory group to IASSW regarding school social worker education in Illinois, is composed of faculty representatives from various universities with accredited schools of social work.

Appropriate Institutional Review Board approval was obtained, and SSWs were invited to participate through the IASSW listserv. Because SSWs in Illinois are not required to hold IASSW membership, only current members $(n=772)$ were invited to participate in this research opportunity. SSWs received an email explaining the study with an attached link providing access to the online survey via Survey Monkey for approximately 4 weeks. To encourage participation, a follow-up reminder was sent by email at the end of the third week. Although the survey yielded a total of 313 responses 
(for an initial response rate of $41 \%$ ), a significant portion of the surveys were incomplete. Only 192 individuals replied to all of the questions; only these cases were included in the data analysis, producing a final response rate of $25 \%$.

Analyzing and coding of responses consisted of identifying key issues focused on by the SSWs. A thematic analysis procedure involving coding and recoding the data was used (Braun \& Clarke, 2006; Miles \& Huberman, 1994; Patton, 2001). Content analysis focused on identifying themes and patterns in participants' responses. Themes that emerged most frequently were considered to reflect factors that contributed to SSWs' perceptions and formed a comprehensive picture of their collective experience. Topics that were mentioned infrequently were revisited to see if they could be incorporated as a sub-theme or should be discarded. This data-driven analysis process required constant comparison as referred to by Strauss and Corbin (1998).

Co-analyst triangulation was used to validate themes and strengthen the trustworthiness of the findings (Lauri, 2011; Patton, 2001). Co-analyst triangulation provided an opportunity for both authors to understand multiple ways of seeing the data and hence avoid selective perception and illuminate blind spots. When disagreements arrived, both authors provided additional perspectives to review the themes and thus achieve a final coding. This method of organizing and triangulating data was used to ensure a well-developed and comprehensive analysis of SSWs' roles, responsibilities, and perceptions regarding RTI/MTSS.

\section{Results}

Demographic characteristics of the survey respondents varied greatly. Thirty-three percent of the SSWs (the largest group) had between one and five years of total work experience while only 9 percent had 21 or more years in their current position. The largest group of respondents (42.7\%) were employed in rural/small towns, with $40 \%$ in suburban locations, and $13 \%$ in urban areas. Most respondents (73\%) worked with elementary students, whereas $44 \%$ worked with middle school students. About one-third worked with early childhood (33\%) and high school (35\%) students, respectively.

The majority (95.3\%) of the 192 respondents reported working in schools currently implementing RTI/MTSS. Interestingly, although RTI/MTSS is mandated in the state of Illinois, $4.7 \%$ of the schools were not implementing interventions. Respondents varied in the extent to which they were involved in the RTI/MTSS process: $42 \%$ reported a great extent of involvement, $40.6 \%$ were somewhat involved, $12.5 \%$ had very little involvement, and $4.6 \%$ had no involvement. Respondents reported that the nature and type of RTI/MTSS implementation varied based on school and district levels. Fifty-seven percent of the SSWs revealed differences in how RTI/MTSS is implemented in the elementary, middle, and high school grades. The results demonstrated a divide between SSWs--some eagerly embraced RTI/MTSS and others reluctantly tackled the systems changes. The implementation of RTI/MTSS was described by respondents as both enhancing and altering the role of SSWs. 


\section{School Social Worker Roles}

SSWs who were already a part of RTI/MTSS in their schools felt that their responsibilities had changed dramatically by allotting more opportunities to share their input and multi-faceted knowledge about students. SSWs were viewed by school staff as functioning as coaches, consultants, or leaders. SSWs shared experiences of being an integral part of the RTI/MTSS team to implement interventions to address significant behavior concerns. According to one individual, "a lot of the work on the secondary and tertiary levels is left to the social worker." For example, respondents noted their social work roles had expanded to include behavioral observations, teacher consultations, and increased prevention work with general education students. Additionally, SSWs were frequently in charge of managing and coordinating collection and dissemination of schoolwide data. Previously they were responsible only for their own data, counseling, and evaluation.

The survey revealed that $72.4 \%$ of respondents felt RTI/MTSS did not limit SSWs roles and responsibilities but required explicit organization and balance. Some respondents who worked in a cooperative district commented that RTI/MTSS made it more difficult to meet special education mandates in a timely fashion while managing daily RTI/MTSS responsibilities. "I am responsible for implementing tier two social and academic instruction groups while also serving as the tier two building coach. This includes implementing Positive Behavioral Interventions and Supports (PBIS) Check-in and Checkout, which minimize time to facilitate therapeutic groups." In addition to limiting the amount of time available for counseling, the majority of respondents felt that RTI/MTSS would replace the necessity of completing Social Developmental Studies (SDS). These respondents feared that eliminating SDS would ultimately lead to fewer special education referrals in the future by limiting the opportunity for social workers to share their input about students. Other respondents, however, felt that the heavy reliance on data-driven assessments represented an improvement over previous practice because it facilitated earlier completion of SDS.

\section{Advantages of RTI/MTSS}

Respondents noted several advantages of RTI/MTSS by selecting from predetermined options on the survey, with opportunities to provide examples. The most frequently noted potential advantages in implementing RTI/MTSS were in providing school-wide behavior supports (90.1\%) and problem-solving interventions (89.6\%). Interestingly, heavy emphasis on data to guide implementation of RTI/MTSS was viewed as an advantage by $77 \%$ of SSWs. This response indicated positive reactions to using data to help schools determine student interventions. Some of the responses for "other" advantages included feeling that RTI/MTSS has led to improved dialogue systems, more consultation opportunities and input regarding students, and enhanced parental involvement and community awareness. Some respondents indicated that RTI/MTSS encouraged open discussions and consultation between disciplines. "RTI is increasing my role and responsibilities. I work more closely with teachers and parents." Some SSWs noted experiences of collaborating with school psychologists to implement behavioral and reading interventions. This open dialogue also encouraged other staff to approach SSWs

with questions about students or to inquire about resources and additional intervention 
strategies. These conversations resulted in explicit goals for all involved (i.e., students, staff, and parents), a structured timeline, and greater clarity throughout implementation stages. Respondents also shared that SSWs were a great asset to parents by encouraging parental involvement and participation in the RTI/MTSS process. Additionally, SSWs also provided community awareness and education about RTI/MTSS implementation and its advantages.

\section{Challenges of RTI/MTSS}

Survey respondents noted many concerns involving RTI/MTSS implementation that seemed to outweigh its potential advantages. Concerns included the lack of social work involvement in RTI/MTSS planning, the implementation process, confusion over intervention tier selection, imbalance between academics and behaviors, data collection, and inadequate training and guidance. These issues are typical of the complexities associated with school-wide changes.

RTI/MTSS Planning. Respondents declared that SSWs are not usually involved in the initial planning and development phases of RTI/MTSS. However, they are called on later to lead the implementation of interventions at tiers two and three. "Staff come to me now with concerns about general education students; I educate the teachers and staff about RTI/MTSS.” One SSW noted, "I am responsible for arranging interventions, planning schedules and behavioral referrals, and problem-solving for both behavior and academic sides of RTI/MTSS.” Other respondents noted that SSWs and psychologists were also responsible for training, consulting, and modeling RTI/MTSS implementation within their districts.

Implementation Process. SSWs perceived that RTI/MTSS implementation is an overwhelming process. "It is time-consuming, labor-intensive, especially at the beginning, and quite inconsistent." Another respondent shared, "Having to attend additional meetings and being placed in a leadership role as RTI/MTSS building coordinator took valuable time away from direct social work services." SSWs identified challenges associated with providing services to students with and without an Individualized Education Program. "I am involved in all aspects of RTI and with all students, not just with special education." These time constraints were even more intensified for SSWs employed in cooperative school districts (i.e., multiple schools that share pupil personnel resources). Some respondents remarked that many challenges are faced at different levels during the implementation phase. "It seems to be implemented differently everywhere depending upon who is in charge, who is dispersing the information, and who is implementing it." Other implementation concerns included the need for precise methods to monitor progress and ensure fidelity, inadequate time for implementation, lack of sufficient funding, and the absence of a collaborative effort from the entire RTI/MTSS school team to move the process forward.

Interventions. Respondents indicated that funding for interventions, especially those designed for special education services, was a pivotal issue. They provided various examples of how RTI/MTSS interventions were limited in some districts due to inadequate data-gathering practices or lack of staff. Other critical concerns regarding interventions included difficulties for students transferring between schools. For example, schools in 
various districts may be at different stages of RTI/MTSS implementation which could lead to barriers in overall systems flow. Further, difficulties with RTI/MTSS interventions were associated with a lack of administrative support. Other respondents noted a lack of consistency in how schools applied social and emotional interventions. For example, some respondents noted a dearth of tier three interventions to meet the needs and demands of students with significant mental health concerns.

Other challenges of the process included difficulty in gauging improvements or quantifying effectiveness and difficulties in finding evidence-based interventions. For example, some respondents reported that SSWs were given a narrow list of options that could be used to assess the effectiveness of interventions. "Sometimes it is difficult to implement interventions that would support pre and post-tests for progress monitoring, thus limiting the use of such tools for social workers." According to one respondent, "not all issues that social workers deal with in a school setting could be quantified or assessed for improvement, which in some ways seems to limit the role of RTI/MTSS." Another respondent stated, "Providing tier one support with a social emotional learning curriculum is emphasized." However, many respondents revealed that demands to provide tier two and tier three interventions services were also increasing. Other respondents commented that making distinctions within a tier system, especially between tiers two and three, was difficult in the absence of well-developed behavioral guidelines. For example, schools with clear guidelines denote the number of behavioral referrals required to move to the next tier. Additionally, if progress monitoring data do not indicate improvement within a specified period, consideration is given towards movement to the next tier.

Behavioral Side of RTI/MTSS. Respondents commented that the behavioral side of RTI/MTSS interventions was not as well developed as those on the academic side. They noted few specific behavioral interventions beyond PBIS and Check \& Connect. The survey revealed that some districts emphasized the academic side of RTI/MTSS more than the behavioral side. "Since we don't have a behavioral system in place, it makes RTI very confusing as to what the expectations are.” Respondents also thought that the behavioral side of RTI/MTSS was critical but time-consuming and difficult to address for some students with multiple and intense academic and behavioral issues. For example, some respondents revealed that there was a greater need for more precise decision-making rules to differentiate when students should move from one tier to the next. This lack of clarity made implementation of behavioral interventions more challenging.

Some respondents also reported that their schools did not have a solid tier one behavioral management system in place. This limited the focus of RTI/MTSS to the academic side, thus heightening the need for additional manpower to collect and maintain behavioral data during implementation. One respondent stated that "teachers are more academic-focused, but SSWs focus more on behavior functioning, which sometimes creates confusion." Another respondent noted, "I am constantly creating individual behavior plans and classroom plans. I also do a lot more classroom groups.”

Data Collection. The survey revealed that not all schools could invest in costly data management systems despite the need to maintain and store information. Some respondents felt that too much time and effort was being wasted in collecting unimportant data. The respondents commented that insufficient data collection processes ignored important areas 
that needed attention and focus, which led to a lack of understanding of "big picture" issues concerning home, school, and community connections. "Way too much time is wasted on measures which do not tell a whole story and is not always a student's primary need." Over-reliance on certain types of data was also viewed as a barrier as "it detracts from other measures of progress, such as psychological assessments or behavior rating scales.”

Despite their reservation about the methods used, respondents also recognized the positive value of data collection processes. They acknowledged that data provided necessary evidence to make the right decisions and also assisted in identifying early interventions and prevention strategies. Nevertheless, collecting the amount of data needed at each point of the process and framing social work goals were perceived to be timeconsuming. As one respondent stated, "it is exhausting to gather data that really shows improvement in social and emotional interventions."

Training and Guidance. Ninety percent of the survey respondents indicated a strong desire for obtaining further information and training about RTI/MTSS. Three-quarters (74\%) noted that they had attended RTI/MTSS training, but most wanted further education on its key elements. Respondents participated in trainings provided by school districts, IASSW conferences, free-standing workshops, and various other entities such as PBIS Network, Illinois Alliance for School-based Problem-solving and Intervention Resources in Education, graduate schools, and the Illinois State Board of Education. Despite a high percentage of respondents partaking in RTI/MTSS trainings, many felt the instruction was limited and lacked ongoing guidance and support throughout implementation. For example, one respondent commented that "there is little follow-up to formal training which makes it difficult.” Overall, many SSWs expressed a need for more guidance on their new roles concerning RTI/MTSS.

\section{Limitations}

There are several limitations of this study suggesting that the findings should be interpreted with caution. Limitations include potential sampling biases related to the pool of respondents and online survey methodology used in this study. Because respondents were drawn from IASSW membership lists, this pool cannot be generalized to the entire population of Illinois SSWs. The sample was based on those members who self-selected to participate; therefore, it introduces the possibility of information bias. While $82.7 \%$ of the 192 respondents worked in rural and suburban communities in Illinois, their perceptions are most likely influenced by location and employment demographics. Likewise, the response rate of $25 \%$ posed a limitation as findings cannot be generalized to the entire population of Illinois SSWs. The use of an online survey may have also served as a limitation by discouraging those less comfortable with technology from participating.

\section{Conclusion}

SSWs are integral trailblazers at their schools with essential responsibilities in creating a true educational community. This study offers a unique perspective of role transformation and underscores what SSWs in Illinois experienced while implementing RTI/MTSS. The results demonstrate recurring themes in RTI/MTSS implementation as many school personnel are unsure about the potential gains. While some advantages of implementing 
RTI/MTSS were identified, SSWs discussed many obstacles and challenges, such as intervention imbalance between academics and behaviors, difficulties regarding data collection, insufficient involvement in planning, and inadequate training. SSWs have training in managing systems change and are particularly suited for implementing RTI/MTSS; unfortunately, they are frequently not called upon to contribute this expertise. The findings suggest that schools are in need of RTI/MTSS data management support to properly address the challenges of addressing students' social and emotional needs. Clear goals for staff and parents are needed as well as a structured timeline for interventions. Such guidelines are necessary to provide clarity to stakeholders throughout RTI/MTSS implementation stages, potentially resulting in more appropriate and available student services and better academic outcomes.

Although some SSWs were resistant to implementing RTI/MTSS, many eventually came to see its potential for improving students' academic outcomes and that it offered them an opportunity to become leaders of this systems change. Consistent with the literature, RTI/MTSS has strengthened the role of SSWs in many ways by enhancing their responsibilities as consultants, coaches, and leaders (Clark \& Tilly, 2010). In these roles, SSWs are seen as knowledge providers who act as a primary source of information on RTI/MTSS for teachers and parents (Clark et al., 2010; Massat, Constable, \& Thomas, 2009; Raines, 2010). For example, SSWs are viewed as providing strong support to teachers for case documentation and planning. SSWs are also entrusted to solve problems or address issues that no one else in the organization can or wants to address. Essentially, changes in the organization are triggering changes in the roles of SSWs.

A surprising finding of this study indicated SSWs' perceptions of leading their school as an RTI/MTSS change champion. Despite the many implementation barriers, this new revelation led to an "ah-ha" moment for SSWs as they recognized the RTI/MTSS the potential leadership advantages outweighed the challenges previously noted. Many essential aspects of managing change require SSWs to use their specialized knowledge and skills to reframe their role as change leaders. Because SSWs understand the need for a collaborative change process, they are well-equipped to advocate and contribute to the performance of the whole school as RTI/MTSS change champions.

\section{Implications}

The findings from this study could have important implications for SSWs. However, it is important to keep in mind that this study used a small sample of 192 survey respondents mostly from small towns and suburban communities in Illinois; therefore, the results should only be generalized to populations that closely resemble this sample. Although there are potentially important extrapolations that could be made from this study, the topic requires more rigorous research to thoroughly understand how SSWs participate in implementing RTI/MTSS. It is critical that SSWs understand and maximize their new opportunities to effectively manage systems change (Clark \& Tilly, 2010). Consistent with the literature, SSWs have begun lending their expertise in facilitating organizational change as well as designing, implementing, and evaluating the impact of services (Dupper, 2003). SSWs must continue to develop collaborative relationships with other professionals to benefit students and employ effective leadership strategies that are deeply embedded within the profession. Embracing additional leadership responsibilities creates ample opportunities 
for SSWs to closely align social and emotional practices with academic achievement (Clark \& Alvarez, 2010; Kelly et al., 2010). Moreover, accepting the challenge to be change champions allows SSWs to exert influence by creatively guiding schools through the RTI/MTSS process.

Based on the number of foundational changes to roles identified by respondents, RTI/MTSS presents SSWs with an opportunity to embrace their new responsibilities and role of a change champion (Avant, 2014). Consistent with the literature, taking action beyond simply complaining is paramount (Winfrey, 2011). RTI/MTSS is here to stay, thus requiring SSWs to either step up as leaders and adapt to the changing landscape of schools or be relegated to the sidelines. As champions of change, SSWs must anticipate RTI/MTSS challenges and meet them with determination and perseverance.

\section{References}

Alfred, L., Slovak, K., \& Broussard, C. (2010). School social workers and a renewed call to advocacy. School Social Work Journal, 15(1), 1-20.

Alvarez, M., \& Anderson-Ketchmark, C. (2010). Review of an evidence-based school social work intervention: Check \& Connect. Children \& Schools, 32(2), 125-127. doi: http://dx.doi.org/10.1093/cs/32.2.125

Avant, D. W. (2014). The roles of school social workers in implementation of Response to Intervention. School Social Work Journal, 38(2), 11-31.

Batsche, G., Elliott, J., Graden, J. L., Grimes, J., Kovaleski, J. F., Prasse, D. et al. (2006). Response to intervention: Policy considerations and implementation. Alexandria, VA: National Association of State Directors of Special Education.

Braun, V., \& Clarke, V. (2006). Using thematic analysis in psychology. Qualitative Research in Psychology, 3, 77-101. doi: http://dx.doi.org/10.1191/1478088706qp063oa

Bridgeland J., Bruce, M., \& Hariharan, A. (2013). The missing piece: A national teacher survey on how social and emotional learning can empower children and transform schools. A report for CASEL. Retrieved from http://static.squarespace.com/static/513f79f9e4b05ce7b70e9673/t/526a2589e4b 01768fee91a6a/1382688137983/the-missing-piece.pdf

Brown-Chidsey, R., \& Steege, M. W. (2005). Response to intervention: Principles and strategies for effective practice. New York, NY: Guilford Press.

Burns, M. K., Wiley, H. I., \& Viglietta, E. (2008). Best practices in implementing effective problem-solving teams. In A. Thomas \& J. Grimes (Eds.), Best practices in school psychology (pp. 1633-1644). Bethesda, MD: National Association of School Psychologists.

Center for Mental Health in Schools at UCLA. (2011). Moving beyond the three tier intervention pyramid toward a comprehensive framework for student and learning supports. Retrieved from http://smhp.psych.ucla.edu/pdfdocs/briefs/threetier.pdf 
Clark, J., \& Alvarez, M. (2010). Response to Intervention: A call to action. In J. Clark \& M. Alvarez (Eds.), Response to Intervention: A guide for school social workers (pp. 257-261). New York, NY: Oxford University Press.

Clark, J., Alvarez, M., Marckmann, W., \& Timm, A. (2010). Supporting the adoption, implementation, and sustainability of RtI systems. In J. Clark \& M. Alvarez (Eds.), Response to Intervention: A guide for school social workers (pp. 232-256). NY: Oxford University Press.

Clark, J., \& Tilly, W. (2010). The evolution of Response to Intervention. In J. Clark \& M. Alvarez (Eds.), Response to Intervention: A guide for school social workers (pp. 318). NY: Oxford University Press.

Crone, D., Hawken, L., \& Horner, R. (2010). Responding to problem behavior in schools: The behavior education program ( $2^{\text {nd }}$ ed.). NY: Guilford.

Dupper, D. (2003). School social work: Skills \& interventions for effective practice. Hoboken, NJ: Wiley.

Eber, L., Lindsey, B. C., \& White, M. (2010). Tier 3 case example: Wraparound. In J. Clark \& M. Alvarez (Eds.), Response to Intervention: A guide for school social workers (pp. 167-190). NY: Oxford University Press.

Evans, R. (2000). The authentic leader. In M. Grogan \& M. Fullan (Eds.), The JosseyBass reader on educational leadership (pp. 287-308). San Francisco, CA: JosseyBass.

Frey, A. J., Lingo, A., \& Nelson, C. M. (2008). Positive behavior support: A call for leadership. Children \& Schools, 30, 5-14. doi: http://dx.doi.org/10.1093/cs/30.1.5

Fullan, M. (2007). The new meaning of educational change ( $4^{\text {th }}$ ed.).NY: Teachers College Press.

Greenfield, R., Rinaldi, C., Proctor, C., \& Cardarelli, A. (2010). Teachers’ perceptions of a Response to Intervention (RTI) reform effort in an urban elementary school: A consensual qualitative analysis. Journal of Disability Studies, 21(1), 47-63.

Harris, M., Franklin, C., \& Lagana-Riordan, C. (2010). The design of social work services. In P. Allen-Meares (Ed.), Social work services in schools (6 $6^{\text {th }}$ ed., pp. 278321). Boston, MA: Allyn \& Bacon.

Hawken, L., \& Horner, R. (2003). Evaluation of a targeted group intervention within a school-wide system of behavioral support. Journal of Behavioral Education, 12, 225240. doi: http://dx.doi.org/10.1023/A:1025512411930

Kelly, M., Frey, A., Alvarez, M., Berzin, S., Shaffer, G., \&, O’Brien, K. (2010). School social work practice and response to intervention. Children \& Schools, 32(4), 201209. doi: http://dx.doi.org/10.1093/cs/32.4.201

Knight, J. (2009). What can we do about teacher resistance? Phi Delta Kappan, 90(7), 508-513. doi: http://dx.doi.org/10.1177/003172170909000711

Kotter, J. P. (1996). Leading change. Boston, MA: Harvard Business School Press. 
Landon, D. (2010). Impact of teacher concerns on Response to Intervention implementation. Unpublished Dissertation, University of Missouri-Columbia, Columbia, MO.

Lauri, M. (2011). Triangulation of data analysis techniques. Papers on Social Representations, 20, 34.1-34.15.

Lawson, H. (2010). Needs and opportunities for social work leadership in emergent P-16 initiatives. Children \& Schools, 32(1), 51-60. doi: http://dx.doi.org/10.1093/cs/32.1.51

Lindsey, B. C. (2008). Looking at positive behavior interventions and supports through the lens of innovations diffusion. The Innovation Journal, 13(2), 1-18. Retrieved from http://www.innovation.cc/scholarly-style/lindsey pbis article7final.pdf

Lunenburg, F. C., \& Ornstein, A. C. (2007). Educational administration: Concepts and practices ( $5^{\text {th }}$ ed.). Belmont, CA: Wadsworth

Malloy, J. M., Sundar, V., Hagner, D., Pierias, L., \& Viet, T. (2010). The efficacy of the RENEW model: Individualized school-to-career services for youth at risk of school dropout. Journal of At-Risk Issues, 15(2), 19-26.

Massat, C. R., Constable, R., \& Thomas, G. (2009). Response to Intervention (RtI) and the school social worker. In C. R. Massat, R. Constable, S. McDonald, \& J. Flynn (Eds.), School social work: Practice, policy and research (pp. 523-531). Chicago, IL: Lyceum.

McIntosh, K., Campbell, A. L., Carter, D. R., \& Dickey, C. R. (2009). Differential effects of a tier two behavior intervention based on function of problem behavior. Journal of Positive Behavior Interventions, 11(2), 82-93. doi: http://dx.doi.org/10.1177/1098300708319127

Miles, M., \& Huberman, A. (1994). Qualitative data analysis ( $2^{\text {nd }}$ ed.). Thousand Oaks, CA: Sage.

Nellis, L. (2012). Maximizing the effectiveness of building teams in Response to Intervention implementation. Psychology in the Schools, 49(3), 245-256. doi: http://dx.doi.org/10.1002/pits.21594

Patton, M. (2001). Qualitative research and evaluation methods ( $3^{\text {rd }}$ ed.). Thousand Oaks, CA: Sage.

Peckover, C., Vasquez, M., Van Housen, S., Saunders, J., \& Allen, L. (2013). Preparing school social workers for the future: An update of school social workers' tasks in Iowa. Children \& Schools, 35(1), 9-17. doi: http://dx.doi.org/10.1093/cs/cds015

Raines, J. C. (2004). Evidence-based practice in school social work: A process in perspective. Children \& Schools, 26, 71-85. doi: http://dx.doi.org/10.1093/cs/26.2.71

Raines, J. C. (2008). Evidence-based practice in school mental health: A primer for school social workers, psychologists, and counselors. New York, NY: Oxford University Press. doi: http://dx.doi.org/10.1093/acprof:oso/9780195366266.001.0001 
Raines, J. C. (2010). Evidence-based school social work practice and response to intervention. In J. Clark \& M. Alvarez (Eds.), Response to Intervention: A guide for school social workers (pp. 208-231). NY: Oxford University Press.

Ridgeway, T. R., Price, D. P., Simpson, C. G., \& Rose, C. A. (2012). Reviewing the roots of response to intervention: Is there enough research to support the promise? Administrative Issues Journal: Education, Practice \& Research, 2(1), 83-95.

Rogers, E. (2003). Diffusion of innovations ( $5^{\text {th }}$ ed.). NY: Free Press.

Sabatino, C., Kelly, E., Moriarity, J., \& Lean, E. (2013). Response to Intervention: A guide to scientifically based research for school social work services. Children in Schools, 35(4), 213-223. doi: http://dx.doi.org/10.1093/cs/cdt017

Scott, T. \& Eber, L. (2003). Functional assessment and wraparound as systemic school processes: Primary, secondary, and tertiary systems examples. Journal of Positive Behavior Intervention and Supports, 5, 31-43. doi: http://dx.doi.org/10.1177/10983007030050030201

Strauss, A., \& Corbin, J. (1998). Basics of qualitative research: Grounded theory procedures and technique ( $2^{\text {nd }}$ ed.). Newbury Park, CA: Sage.

Sugai, G., \& Horner, R. (2002). The evolution of discipline practices: School-wide positive behavior supports. Child \& Family Behavior Therapy, 24(1/2), 23-50. doi: http://dx.doi.org/10.1300/J019v24n01 03

Sugai, G., \& Horner, R. H. (2010). School-wide positive behavior support: Establishing a continuum of evidence-based practices. Journal of Evidence-based Practices for Schools, 11(1), 62-83. doi: http://dx.doi.org/10.1300/J019v24n01_03

Sugai, G., Horner, R. H., \& Gresham, F. M. (2002). Behaviorally-effective school environments. In M. R. Shinn, H. M. Walker \& G. Stoner (Eds.), Interventions for academic and behavior problems II: Preventive and remedial approaches (pp. 315350). Bethesda, MD: National Association of School Psychologists.

University of South Florida. (2011). Implementing a multi-tiered system of support for behavior: Recommended practices for school and district leaders. Retrieved from http://flpbs.fmhi.usf.edu/pdfs/RTIB\%20Guide\%20101811_final.pdf

Winfrey, D. (2011). Unwrapping tradition: Shifting from traditional leadership to transformative action. In C. M. Shields (Ed.), Transformative leadership: A reader (pp. 114-130). NY: Peter Lang.

Zosky, D., Avant, D.W. \& Thompson, J. (2014). Social work and special education students' attributions of poverty: A leadership opportunity for school social workers. School Social Work Journal, 38(2), 77-97.

\section{Author note}

Address correspondence to: Deneca Winfrey Avant, $\mathrm{PhD}$, Illinois State University, School of Social Work, Campus Box 4650, 326 Rachel Cooper Hall, Normal, IL 61790.

E-mail: $\underline{\text { dwinfre@ilstu.edu }}$ 